\title{
Acute management of traumatic spinal cord injury in a Greek and a Swedish region: a prospective, population-based study
}

\author{
A Divanoglou ${ }^{1}, \AA^{\text {S Seiger }}{ }^{1}$ and R Levi ${ }^{1,2}$ \\ ${ }^{1}$ Division of Neuro-rehabilitation, Department of Neurobiology, Care Sciences and Society, Karolinska Institutet, Stockholm, \\ Sweden and ${ }^{2}$ Division of Rehabilitation Medicine, Umea University, Umeä, Sweden
}

\begin{abstract}
Study design: Prospective, population-based study. This paper is part of the Stockholm Thessaloniki Acute Traumatic Spinal Cord Injury Study (STATSCIS).

Objectives: To characterize patient populations and to compare acute management after traumatic spinal cord injury (TSCl).

Settings: The Greater Thessaloniki region in Greece and the Greater Stockholm region in Sweden. Methods: Inception cohorts with acute TSCI that were hospitalized during the study period, that is September 2006 to October 2007, were identified. Overall, 81 out of 87 cases consented to inclusion in Thessaloniki and 47 out of 49 in Stockholm. Data from Thessaloniki were collected through physical examinations, medical record reviews and communication with TSCI cases and medical teams. Data from Stockholm were retrieved from the Nordic Spinal Cord Injury Registry.

Results: There were no significant differences between study groups with regard to core clinical characteristics. In contrast, there were significant differences in (1) transfer logistics from the scene of trauma to a tertiary-level hospital (number of intermediate admissions, modes of transportation and duration of transfer) and (2) acute key therapeutic interventions, that is, the use of mechanical ventilation (49\% in Thessaloniki versus $20 \%$ in Stockholm), and performance of tracheostomy (36\% in Thessaloniki versus $15 \%$ in Stockholm); spinal surgery was performed significantly more often and earlier in Stockholm than in Thessaloniki.

Conclusions: Despite largely similar core clinical characteristics, Stockholm and Thessaloniki cases underwent significantly different acute management, most probably to be attributed to adaptations to the differing regional approaches of care one following a systematic approach of $\mathrm{SCl}$ care and the other not. Spinal Cord (2010) 48, 477-482; doi:10.1038/sc.2009.160; published online 22 December 2009
\end{abstract}

Keywords: clinical characteristics; epidemiology; respiratory therapy; spinal injury unit; $\mathrm{SCl}$ system of care

\section{Introduction}

This paper presents part of a comparative study on traumatic spinal cord injury (TSCI), the so-called Stockholm Thessaloniki Acute Traumatic Spinal Cord Injury Study (STATSCIS), in two European Union countries, namely Greece and Sweden.

Traumatic SCI management during the first days posttrauma has been addressed in several clinical and experimental studies. ${ }^{1,2}$ Acute TSCI management starts at the scene of trauma, with the aim of limiting the extent of injury, handling its acute consequences, and preventing complications. $^{3}$ Managing TSCI in spinal injury units (SIUs) as compared with fragmented care in general health-care

Correspondence: A Divanoglou, Division of Neuro-rehabilitation, Karolinska Institutet, Frösundaviks allé 13, 16989, Stockholm, Sweden.

E-mail: anestis.divanoglou@ki.se

Received 20 January 2009; revised 1 September 2009; accepted 23 October 2009; published online 22 December 2009 facilities has been shown to be of benefit. ${ }^{4-6}$ While Sweden has six SIUs, TSCI in Greece is managed in various nonspecialized surgical and orthopaedic wards.

The Consortium for Spinal Cord Medicine has recently compiled a Clinical Practice Guideline for Health-Care Professionals, the so-called 'Early acute management in adults with spinal cord injury' ${ }^{3}$ This publication underscores the importance of adequate acute management for the achievement of optimal outcomes.

Both prompt and correct diagnosis of TSCI is crucial for subsequent management. Accurate clinical examination according to the International Standards for Neurological Classification for Spinal Cord Injury ${ }^{7}$ is also highly relevant, especially during the acute phase, as it contributes to decision making.

We have previously presented the demographic and epidemiological characteristics of the two study cohorts in 
Thessaloniki and Stockholm. ${ }^{8}$ The aim of this second paper is specifically to assess clinical characteristics and acute management in the regions under study.

\section{Materials and methods}

A detailed description of the methodology of STATSCIS has been previously published. ${ }^{8}$

\section{Settings}

The 'Greater Thessaloniki region' (Thessaloniki) comprises Central and West Macedonia in Greece, whereas the 'Greater Stockholm region' (Stockholm) comprises Stockholm and Gotland Counties in Sweden. The two regions have a similar population size of $\sim 2$ million, with Thessaloniki being about three times larger area wise than Stockholm.

\section{Inclusion criteria}

All of the following criteria had to be satisfied for inclusion in both regions: (1) acute traumatic spinal cord or cauda equina lesion, (2) age $\geqslant 16$ years at the time of injury, (3) inpatient care at a hospital of Thessaloniki or Stockholm at some time between September 2006 and October 2007, (4) survival for at least 7 days post trauma, (5) being resident of the country of the respective region and (6) case giving informed consent for STATSCIS.

\section{Material}

Overall, 81 out of 87 (93\%) consecutive cases with acute TSCI in Thessaloniki and 47 out of 49 (95\%) in Stockholm consented to participate in the study.

\section{Data collection and analysis}

To satisfy the aims of STATSCIS, we implemented the Nordic Spinal Cord Injury Registry (NSCIR) data set in Thessaloniki. In Stockholm, the NSCIR data set is routinely being used since many years. NSCIR comprises scientifically and clinically relevant data according to international standards. ${ }^{9}$

Each case was individually followed up during the first year after trauma. A subset of the NSCIR consisting of the Acute Form and the Neurological Assessment Form was used for this paper (http://www.nscic.se). Additional detailed data regarding the transfer from the scene of trauma to arrival at a tertiary-level hospital were documented (for example, intermediate transfers, modes of transportation and duration of transfer). Operational definitions of the terms are provided in Table 1.

In brief, the subset of the Acute Form that was used in this study is divided into four parts, each including several variables: (1) pre-hospital phase (including date, location and external cause of injury), (2) clinical status and management at the first hospital of admission (including level of consciousness (LOC), other vital signs, method of spinal stabilization), (3) clinical status on arrival at the tertiary-level hospital (including LOC, ventilation, diagnosis of SCI, presence/diagnosis of spinal column injury, presence/location/severity of extra-spinal injuries, presence/diagnosis of comorbid spinal and non-spinal disorders) and (4) type and date of key therapeutic interventions (including mechanical ventilation, tracheostomy, corticosteroid treatment, anticoagulant prophylaxis, spinal treatment). In Thessaloniki, the first author (AD) scrutinized all available medical records and Emergency Medical System data, and communicated directly with all cases and medical teams. In Stockholm, all data were retrieved from the NSCIR database.

Table 1 Operational definitions used in the study in cases where a single, internationally accepted definition is lacking

\begin{tabular}{|c|c|}
\hline Term & Definition \\
\hline Core clinical characteristics & $\begin{array}{l}\text { The most fundamental clinical descriptors universally used to define/describe the state of the TSCI patient, such } \\
\text { as level of consciousness, neurological level, ASIA Impairment Scale, presence and severity of extra-spinal injuries, } \\
\text { presence of pre-morbid spinal and comorbid non-spinal disorder }\end{array}$ \\
\hline Intermediate admission & Primary admission from the scene of trauma to a small regional hospital before admission to a tertiary-level hospital \\
\hline \multirow[t]{3}{*}{ Level of consciousness (LOC) } & Normal: GCS $=15$ \\
\hline & Impaired: $14 \leqslant \mathrm{GCS} \leqslant 9$ \\
\hline & Unconscious: GCS $\leqslant 8$ \\
\hline $\begin{array}{l}\text { Pre-morbid non-spinal } \\
\text { disorder }\end{array}$ & $\begin{array}{l}\text { Pre-existing disorder that either directly contributed to the trauma or potentially negatively affected the general } \\
\text { outcome }\end{array}$ \\
\hline Comorbid spinal disorder & $\begin{array}{l}\text { Disorder of the spine that contributed to the occurrence or the extent of } \mathrm{SCl} \text { (for example, spinal stenosis, ankylotic } \\
\text { spondylitis) }\end{array}$ \\
\hline \multirow[t]{3}{*}{ Severity of extra-spinal injuries } & (i) Mild: unlikely to affect early mortality, for example, distal limb fractures \\
\hline & (ii) Serious: likely to affect early mortality if not properly treated, for example, pneumothorax, haemothorax \\
\hline & $\begin{array}{l}\text { (iii) Life-threatening: likely to affect early mortality regardless of } \mathrm{SCl} \text {, even if properly treated, for example, } \mathrm{TBI} \text {, } \\
\text { excessive bleeding }\end{array}$ \\
\hline \multirow[t]{3}{*}{ Mechanical ventilation } & (i) Acutely: provided within the first $24 \mathrm{~h}$ after trauma \\
\hline & (ii) Post-acutely: provided later than the first $24 \mathrm{~h}$ after trauma \\
\hline & $\begin{array}{l}\text { Patients who were intubated only for the operating room and subsequently extubated within } 24 \mathrm{~h} \text { after the operation } \\
\text { were not coded as having received mechanical ventilation for this study }\end{array}$ \\
\hline \multirow[t]{2}{*}{ Tracheostomy } & (i) Early: performed within 7 days after initial intubation \\
\hline & (ii) Late: performed later than 7 days after initial intubation \\
\hline Corticosteroid treatment & $\begin{array}{l}\text { We registered if such treatment was initiated, but not the protocol of treatment (time point of initiation, dose, } \\
\text { duration) }\end{array}$ \\
\hline
\end{tabular}

Abbreviations: GCS; Glasgow Coma Scale; SCI, spinal cord injury; TBI, traumatic brain injury; TSCI, traumatic spinal cord injury. 
The Neurological Assessment Form included a full examination according to the International Standards for Neurological Classification for SCI. ${ }^{7}$ In Thessaloniki, all such examinations for this study were performed by $\mathrm{AD}$. This strategy was followed, as the International Standards were not universally implemented in Greece at the time of the study. AD has 8 years of clinical experience in SCI management, has participated in an official workshop on International Standards examination and has been using this assessment method for several years. The corresponding examinations in Stockholm were performed by physicians and physiotherapists specialized in SCI. For this study, comprehensive neurological examination on admission was performed at a mean time of 20 days after trauma (median $=11$, s.d. $= \pm 19.7)$ in Thessaloniki and 17 days (median $=13$, s.d. $= \pm 17.2$ ) in Stockholm.

To maximize validity and minimize missing data, quality assurance was performed in both regions, that is, by crosschecking data in the registry forms with medical records. All retrieved data were jointly re-evaluated in detail by the authors for medical accuracy and uniform interpretation, for example, with regard to assessment of surgical procedures, extra-spinal injuries and any secondary morbidity.

Descriptive data are presented as $n(\%)$, mean, median and s.d. Statistical significance was set at $P<0.05$. Differences in proportions between regions were examined by $\chi^{2}$-test and Fisher's exact test. Statistical mean differences between regions were determined by independent Student's $t$-test. For ordinal variables or in cases of non-normal distribution, the Mann-Whitney test was used. All statistical analyses were performed using the SPSS software (Statistical Package for the Social Sciences, v. 16.0, Chicago, IL, USA).

\section{Ethics}

Ethical approvals for STATSCIS were obtained by the Human Ethics Committee at Karolinska Institutet, the Hellenic Data Protection Authority, the Nordic SCI Council, the Scientific Committee and the Board of each participating hospital in Thessaloniki.

\section{Results}

Transfer from the scene of trauma to a tertiary-level hospital Cases who were injured outside the respective country under study were excluded from these particular analyses (Table 2). This occurred in six Swedish cases and in none of the Greek cases. In Thessaloniki, transfers were carried out either by road ambulance or by private cars, whereas in Stockholm, air transport was additionally used on nine occasions. Statistically, there were significantly more intermediate admissions in the Greek group, 33 to 1 hospital (41\%) and 12 (15\%) to 2 hospitals, than in the Swedish group, 7 (17\%) to 1 hospital. The mean (s.d.) duration of transfer from the scene of trauma to a tertiary-level hospital was 2 days $( \pm 8.1)$ in Thessaloniki and 0.2 days $( \pm 0.1)$ in Stockholm.

\section{Neurological status}

Approximately $30 \%$ of TSCI cases in each region had a high cervical neurological lesion (C1-C4), 10\% had a low
Table 2 Transfers from the scene of trauma to a tertiary-level hospital (excluding those cases that were injured outside the respective country under study)

\begin{tabular}{|c|c|c|c|}
\hline & $\begin{array}{l}\text { Thessaloniki } \\
\qquad(\mathrm{n}=81) \\
\mathrm{n}(\%)\end{array}$ & $\begin{array}{c}\text { Stockholm } \\
(\mathrm{n}=41) \\
\mathrm{n}(\%)\end{array}$ & P-value \\
\hline \multicolumn{3}{|c|}{ Intermediate admissions (number) } & 0.000 \\
\hline None & $35(43)$ & $34(83)$ & \\
\hline One & $33(41)$ & $7(17)$ & \\
\hline Two & $12(15)$ & $0(0)$ & \\
\hline Six & 1 (1) & $0(0)$ & \\
\hline \multicolumn{3}{|c|}{ Mode of transportation (number) } & 0.000 \\
\hline Private car & 10 & 2 & \\
\hline Road ambulance & 134 & 37 & \\
\hline Helicopter & 0 & 9 & \\
\hline Total number of transfers & 144 & 48 & \\
\hline \multicolumn{3}{|c|}{$\begin{array}{l}\text { Duration of transfer from the scene of trauma to a tertiary-level } \\
\text { hospital (in days) }\end{array}$} & 0.002 \\
\hline 0 & $59(73)$ & $40(98)$ & \\
\hline 1 & $8(10)$ & $1(2)$ & \\
\hline 2 & $2(2)$ & $0(0)$ & \\
\hline$\geqslant 3$ & $12(15)$ & $0(0)$ & \\
\hline
\end{tabular}

Values in bold are those that are statistically significant.

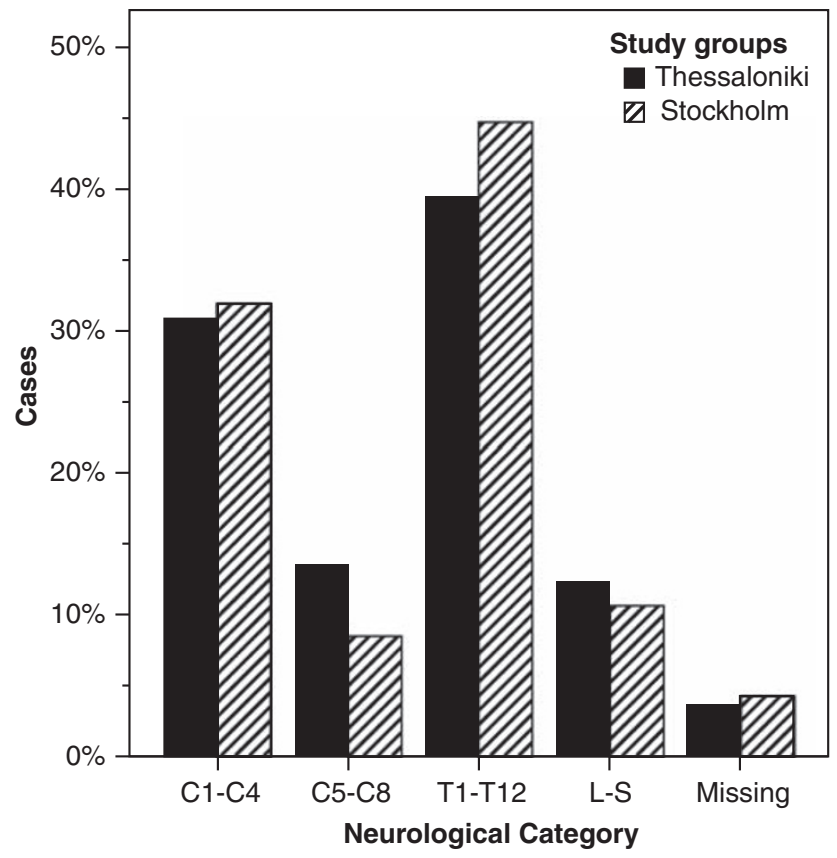

Figure 1 Neurological category distribution in the study groups.

cervical lesion (C5-C8), 40\% a thoracic lesion (T1-T12) and $\sim 10 \%$ a lumbosacral lesion (Figure 1 ). About $5 \%$ could not be confidently classified because of insufficient data. Neurologically complete lesions (ASIA Impairment Scale (AIS) A) occurred in 29 cases (36\%) in Thessaloniki and in 17 cases (36\%) in Stockholm. Neurologically incomplete lesions occurred in 46 cases (57\%) in Thessaloniki (B: $4 \%$, C: 21\%, D: 32\%) and in 26 cases (55\%) in Stockholm (B: 6\%, C: 


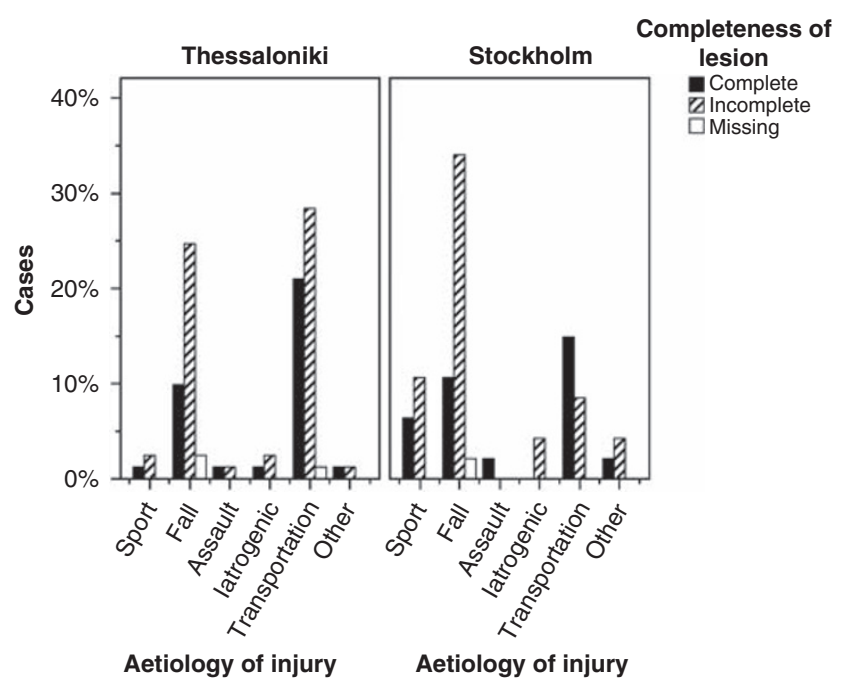

Figure 2 Aetiology of injury in relation to completeness of lesion.

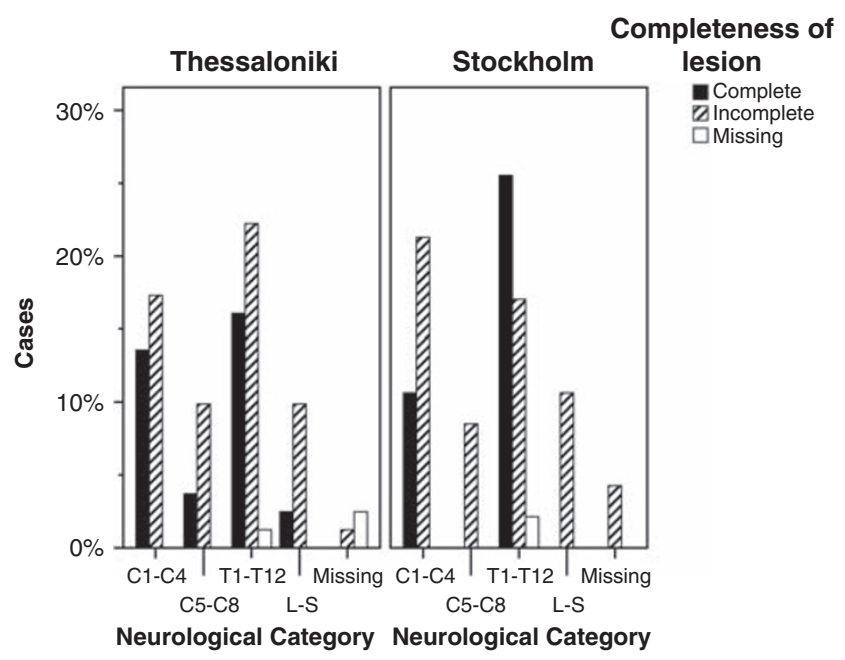

Figure 3 Completeness of lesion in relation to neurological category in the study groups.

19\%, D: 30\%). Data on AIS were unobtainable in six cases in Thessaloniki and in four cases in Stockholm because of various factors, such as the presence of extra-spinal injuries, late case identification and communication problems. When assessing completeness in relation to the aetiology of injury, falls in both regions accounted for proportionally more incomplete than complete injuries, compared with transportation-related injuries (Figure 2).

Overall, no statistically significant differences between study groups were found with regard to distribution of neurological levels, completeness of lesions, means of ASIA Total Motor Score or AIS grading. Moreover, there was no statistically significant difference when assessing the completeness of neurological lesions in relation to the neurological category (Figure 3).
Table 3 Core clinical characteristics

\begin{tabular}{|c|c|c|c|}
\hline & $\begin{array}{l}\text { Thessaloniki } \\
(\mathrm{n}=81) \\
\mathrm{n}(\%)\end{array}$ & $\begin{array}{c}\text { Stockholm } \\
(\mathrm{n}=47) \\
\mathrm{n}(\%)\end{array}$ & P-value \\
\hline $\begin{array}{l}\text { LOC on first hospital admission } \\
\text { Normal } \\
\text { Impaired } \\
\text { Unconscious } \\
\text { Missing }\end{array}$ & $\begin{array}{c}58(72) \\
10(12) \\
6(7) \\
7(9)\end{array}$ & $\begin{aligned} 30 & (64) \\
9 & (19) \\
2 & (4) \\
6 & (13)\end{aligned}$ & 0.540 \\
\hline $\begin{array}{l}\text { Extra-spinal injuries_-present } \\
\text { Extra-spinal injuries_-severity } \\
\text { Mild } \\
\text { Serious } \\
\text { Life-threatening }\end{array}$ & $\begin{array}{l}40(49) \\
0.675 \\
15(19) \\
15(19) \\
10(12)\end{array}$ & $\begin{aligned} 23 & (49) \\
11 & (23) \\
8 & (17) \\
4 & (9)\end{aligned}$ & 0.961 \\
\hline $\begin{array}{l}\text { Extra-spinal injuries_topography } \\
\text { Skull } \\
\text { Upper extremities } \\
\text { Thorax } \\
\text { Abdomen } \\
\text { Pelvis } \\
\text { Lower extremities }\end{array}$ & $\begin{aligned} 16 & (20) \\
11 & (14) \\
25 & (31) \\
5 & (6) \\
6 & (7) \\
9 & (11)\end{aligned}$ & $\begin{aligned} 6 & (13) \\
10 & (21) \\
11 & (23) \\
1 & (2) \\
3 & (6) \\
5 & (11)\end{aligned}$ & $\begin{array}{l}0.344 \\
0.323 \\
0.419 \\
0.413 \\
1.000 \\
1.000\end{array}$ \\
\hline $\begin{array}{l}\text { Comorbid spinal disorder-present } \\
\text { Spinal stenosis } \\
\text { Mb Bechterew } \\
\text { Degenerative spinal disease }\end{array}$ & $\begin{array}{c}32(40) \\
13(16) \\
3(4) \\
19(23)\end{array}$ & $\begin{array}{r}12(26) \\
7(15) \\
2(4) \\
2(4)\end{array}$ & $\begin{array}{l}0.109 \\
0.862 \\
0.877 \\
\mathbf{0 . 0 0 5}\end{array}$ \\
\hline $\begin{array}{l}\text { Pre-morbid non-spinal disorder } \\
\text { Diabetes mellitus } \\
\text { Arteriosclerotic disease } \\
\text { Parkinson's disease } \\
\text { Major psychiatric disorder } \\
\text { Abuse }\end{array}$ & $\begin{aligned} & 6(7) \\
& 10(12) \\
& 3(4) \\
& 4(5) \\
& 3(4)\end{aligned}$ & $\begin{array}{l}1(2) \\
6(13) \\
0(0) \\
3(6) \\
5(11)\end{array}$ & $\begin{array}{l}0.205 \\
0.945 \\
0.182 \\
0.729 \\
0.118\end{array}$ \\
\hline
\end{tabular}

Abbreviation: LOC, level of consciousness.

Values in bold are those that are statistically significant.

Other core clinical characteristics

For 58 cases $(72 \%)$ in Thessaloniki and 30 cases $(64 \%)$ in Stockholm, LOC was normal on first hospital admission according to the medical records (Table 3). Almost half of the cases in both study groups had sustained extra-spinal injuries, classified as 'serious' in 15 cases (19\%) in Thessaloniki and in 8 (17\%) in Stockholm, and as 'life-threatening' in 10 cases $(12 \%)$ in Thessaloniki and in 4 cases (9\%) in Stockholm.

In summary, neither LOC on first hospital admission, nor the presence and severity of extra-spinal injuries, nor the presence of pre-morbid non-spinal disorders were significantly different between study groups. However, comorbid degenerative spinal disease was more common in the Thessaloniki group $(P=0.005)$.

\section{Acute key therapeutic interventions}

Nearly half (49\%) of the cases in Thessaloniki were put on mechanical ventilation; 28 acutely and 12 post-acutely, in contrast to Stockholm where only $20 \%$ were treated with ventilators; 9 acutely and 1 post-acutely (Table 4). Out of those who were put on mechanical ventilation, as many as 7 out of 10 in both regions also underwent a tracheostomy. 
Table 4 Acute key therapeutic interventions

\begin{tabular}{lccc}
\hline & $\begin{array}{c}\text { Thessaloniki } \\
(\mathrm{n}=81) \\
\mathrm{n}(\%)\end{array}$ & $\begin{array}{c}\text { Stockholm } \\
(\mathrm{n}=47) \\
\mathrm{n}(\%)\end{array}$ & P-value \\
\hline Spinal surgery & $63(78)$ & $46(98)$ & 0.002 \\
Additional spinal surgery & $7(9)$ & $4(9)$ & 1.000 \\
Mechanical ventilation & $40(49)$ & $10(21)$ & 0.002 \\
$\quad$ Acute & $28(35)$ & $9(19)$ & \\
Post-acute & $12(15)$ & $1(2)$ & \\
Tracheostomy & $29(36)$ & $7(15)$ & 0.011 \\
$\quad$ Early & $14(17)$ & $4(9)$ & \\
Late & $14(17)$ & $3(6)$ & \\
$\quad$ Unknown & $1(1)$ & $0(0)$ & \\
Corticosteroid treatment & $55(68)$ & $31(66)$ & 0.173 \\
Anticoagulant prophylaxis & $81(100)$ & $45(96)$ & 0.061 \\
\hline
\end{tabular}

Values in bold are those that are statistically significant.

Tracheostomy was performed in 29 cases (36\%) in Thessaloniki; early tracheostomy in 14, late tracheostomy in 14, and unknown in 1, and in 7 cases (15\%) in Stockholm; early tracheostomy in 4 and late tracheostomy in 3. Thus, there were statistically significant differences between the two regions in both of these treatment modalities, $(P=0.002)$ and $(P=0.011)$, respectively.

Spinal surgery was performed in a significantly higher proportion of cases $(P=0.002)$ and at an earlier time point after trauma $(P=0.025)$ in Stockholm than in Thessaloniki. Overall, in Thessaloniki, 63 out of 81 cases (78\%) were operated on after an average of 10 days (median $=4$, s.d. $= \pm 25)$, whereas in Stockholm 46 out of $47(98 \%)$ were operated on after an average of 3 days (median $=1$, s.d. $= \pm 4$ ).

There were no significant differences between study groups with regard to performance of second spinal surgery, administration of anticoagulant prophylaxis and corticosteroid treatment.

\section{Discussion}

This paper evaluates the core clinical characteristics and acute management of all consecutive TSCI cases in Thessaloniki and Stockholm during the study period. To our knowledge, this is the first population-based study evaluating inception cohorts with acute TSCI in Greece and in Sweden. Undoubtedly, the two regions appear with different approaches of care for managing acute TSCI; Stockholm follows a SCI system approach with a centralized and predefined clinical process that includes an SIU, whereas Thessaloniki appears with a generic 'non-system' approach scattered over dozens of wards. With the exception of Thessaloniki being more rural than Stockholm and the difference in the dominant aetiology of injury, but otherwise in the absence of any other major differences between study groups in demographic ${ }^{8}$ and core clinical characteristics, the differences in treatment warrant further elucidation as to their causes.
In acute TSCI, early invasive respiratory interventions (that is, mechanical ventilation and tracheostomy) are performed either as a preventative measure or as treatment of early respiratory failure (in high cervical lesions and/or in multi-trauma patients with serious or life-threatening extraspinal injuries), whereas late invasive respiratory interventions typically are warranted by the occurrence of severe complications. ${ }^{10}$ In this study, statistically significantly more cases in Thessaloniki underwent invasive respiratory treatment compared with cases in Stockholm.

With regard to the timing of spinal surgery, our data show a later timing in the Thessaloniki group compared with the Stockholm group. In a prospective analysis, Papadopoulos et al. ${ }^{11}$ concluded that immediate spinal surgery after acute SCI may significantly improve neurological outcome. In contrast, another prospective study ${ }^{12}$ found no statistical difference in neurological recovery between early $(<72 \mathrm{~h}$ post trauma) and late ( $>5$ days after trauma) spinal surgery groups. McKinley et al. ${ }^{13}$ agreed with the findings of the latter study, but also highlighted the increased length of stay, the increased costs and the higher incidence of pulmonary complications in late surgical interventions. Finally, Fehlings and Perrin ${ }^{14}$ concluded that there are currently no standards regarding the role and timing of decompression in acute SCI. Nevertheless, it has recently been recommended that surgical decompression and stabilization should be performed early after acute TSCI. ${ }^{3,14}$

The design of this study does not allow for a detailed analysis of why type and timing of treatment differs to such a great degree. Nevertheless, we postulate that the differences reflect adaptations to the varying regional conditions of care and not the differing levels of medical skills and equipment.

In Thessaloniki, all cases were transported by road-the three extant helicopters of the National Centre of Emergency Care operate mainly in the islands. ${ }^{15}$ Furthermore, Greek cases had significantly more intermediate admissions and were in transfer for a longer time compared with the Swedish cases. In the absence of an SCI system of care in Thessaloniki, and in the most likely presence of haemodynamic and/or spinal instability, deviations in management from established clinical guidelines are probably to some extent adaptive and unavoidable. The frequent invasive respiratory interventions might thus reflect the need for assuring adequate oxygenation during long-distance transportations, whereas the time-consuming process from the trauma scene to arrival at a tertiary-level hospital may also have contributed to delayed, and perhaps in some instances deterred, spinal surgery.

Updating triage protocols for cases with suspected or diagnosed TSCI, and establishing a comprehensive system of care for acute TSCI in Greece, including regional SIUs, are likely to optimize the chain of events after injury. Establishment of regional SIUs will not only raise awareness of TSCI, but may also coordinate acute management. As suggested by Vitaz et al., ${ }^{16}$ despite the high importance of early surgery, early mobilization and early tracheostomy in the treatment of TSCI, the total coordination of patient care as such is among the most important aspects. In conclusion, 
they stressed that the implementation of a clinical pathway for SCI is not only cost-effective but also ensures better quality of care leading to improved outcomes. Special thought should probably be given to rural settings, where each local catchment area has to develop its own routines on the basis of available resources, as they appear different from urban settings. ${ }^{17}$

In summary, we found statistically significant differences in acute management of TSCI between Stockholm and Thessaloniki. These differences are not explicable in terms of differences in patient characteristics, but rather reflect adaptations to different approaches of care. Subsequent outcome analysis will elucidate the impact of such differences.

\section{Conflict of interest}

The authors declare no conflict of interest.

\section{Acknowledgements}

We thank the Spinalis Foundation for providing financial support to STATSCIS, making it all possible to be conducted. We would also like to thank Sara Runesdotter for assistance in statistics, Ninni Westgren and Tomas Brofelth for the constant close cooperation, and all the collaborators from both regions. The collaborators are GPG Papanikolaou Hospital; Bitzani, Lavrentieva (ICU); Kapravelos, Abatzidou (ICU); Mparoutas, Skoullios (Neurosurgical); Pournaras, Christodoulou (Orthopaedic); Christaki (Respiratory). Ahepa Univ. Hospital; Sofianos, Giala (ICU); Skourtis, Setzis, Ourailoglou (ICU); Harlaftis, Papaavramidis (ICU); Selviaridis, Ioannou, Stavrinou (Neurosurgical). G.P.G. Papageorgiou Hospital; Matamis, Sinnefaki (ICU); Kampelis, Alexiadou (Neurosurgical); Kapetanos, Likomitros (Orthopaedic); Kyriakidis, Moschoglou, Valanos (Orthopaedic); Ippokrateio Hospital; Gerogianni, Efthimiou, Papageorgiou (ICU); Mpallas (ICU); Tsitsopoulos, Tsonidis, Tsitouras (Neurosurgical); Dimitriou, Boursinos (Orthopaedic); the National Centre for Emergency Care; Mpoutlis, Matsikoudi. Karolinska Univ. Hospital; Hedman, Brofelth (SIU); Westgren, Hultling, Eriksson, Werhagen (Spinalis Clinic); Rehab Station Stockholm; Bjelak, Holmström, Lindgren; Stockholms Sjukhem; Kärvestedt, Aly, Westerlund and the Nordic Spinal Cord Injury Council.

\section{References}

1 Hurlbert RJ. Strategies of medical intervention in the management of acute spinal cord injury. Spine 2006; 31: S16-S21.

2 Bernhard M, Gries A, Kremer P, Bottiger BW. Spinal cord injury (SCI) - prehospital management. Resuscitation 2005; 66: 127-139.

3 Consortium SCM. Early acute management in adults with spinal cord injury: A clinical practice guideline for healthcare professionals. J Spinal Cord Med 2008; 31: 403-479.

4 Illis LS. The case for specialist units. Spinal Cord 2004; 42: 443-446.

5 Aito S. Complications during the acute phase of traumatic spinal cord lesions. Spinal Cord 2003; 41: 629-635.

6 Heinemann AW, Yarkony GM, Roth EJ, Lovell L, Hamilton B, Ginsburg $\mathrm{K}$ et al. Functional outcome following Spinal-cord injury - a comparison of specialized Spinal-cord injury center vs general-hospital short-term care. Arch Neurol 1989; 46: 1098-1102.

7 Maynard FM, Bracken MB, Creasey G, Ditunno JF, Donovan WH, Ducker TB et al. International standards for neurological and functional classification of spinal cord injury. Spinal Cord 1997; 35: 266-274.

8 Divanoglou A, Levi R. Incidence of traumatic spinal cord injury in Thessaloniki, Greece and Stockholm, Sweden: a prospective population-based study. Spinal Cord 2009; 47: 796-801.

9 Levi R, Ertzgaard P. Quality indicators in spinal cord injury care: A Swedish collaborative project. Scand J Rehabil Med 1998; 38: $1-80$.

10 Berlly M, Shem K. Respiratory management during the first five days after spinal cord injury. J Spinal Cord Med 2007; 30: 309-318.

11 Papadopoulos SM, Selden NR, Quint DJ, Patel N, Gillespie B, Grube S. Immediate spinal cord decompression for cervical spinal cord injury: Feasibility and outcome. J Trauma 2002; 52: 323-332.

12 Vaccaro AR, Daugherty RJ, Sheehan TP, Dante SJ, Cotler JM, Balderstrom RA et al. Neurologic outcome of early versus late surgery for cervical spinal cord injury. Spine 1997; 22: 2609-2613.

13 McKinley W, Meade MA, Kirshblum S, Barnard B. Outcomes of early surgical management versus late or no surgical intervention after acute spinal cord injury. Arch Phys Med Rehabil 2004; 85: 1818-1825.

14 Fehlings MG, Perrin RG. The timing of surgical intervention in the treatment of spinal cord injury: a systematic review of recent clinical evidence. Spine 2006; 31: S28-S35.

15 Papaspyrou E, Setzis D, Grosomanidis V, Manikis D, Boutlis D, Ressos C. International EMS systems: Greece. Resuscitation 2004; 63: 255-259.

16 Vitaz TW, Mcllvoy L, Raque GH, Spain DA, Shields CB. Development and implementation of a clinical pathway for spinal cord injuries. J Spinal Disord 2001; 14: 271-276.

17 Rogers FB, Shackford SR, Osler TM, Vane DW, Davis JH. Rural trauma: The challenge for the next decade. J Trauma 1999; 47: 802-821. 